\title{
cartografia infantil: enfoques metodológicos seguidos de experiências com crianças e jovens de portugal e brasil ${ }^{1}$
}

\author{
tiago almeida ${ }^{2}$ \\ escola superior de educação do instituto politécnico de lisboa, lisboa, portugal ${ }^{3}$ \\ orcid id: https:// orcid.org/0000-0002-3557-0623 \\ luciano bedin da costa ${ }^{4}$ \\ universidade federal de porto alegre, porto alegre, rio grande do sul, brasil \\ orcid id: https://orcid.org/0000-0002-6350-2644
}

resumo

Este artigo tem um objetivo duplo que se consigna em situar, teórica e empiricamente, a cartografia infantil como metodologia de investigação-intervenção. Situaremos, num primeiro movimento, a cartografia infantil em suas bases epistemológicas e filosóficas, tendo como inspiração as concepções cartográficas da filosofia de Deleuze \& Guattari e seus comentadores. A aposta em uma cartografia junto às infâncias desloca o olhar e o agir de uma pesquisa a dimensões outrora imperceptíveis ou mesmo relegadas a um plano de menor valia. Ao invés de somente se interessar pelo que as infâncias dizem, uma cartografia infantil lança seu mapa sensível às forças que estão imbricadas nestes dizeres, forças que se revelam no processo de convivência das infâncias com o aparato humano e inumano que circunscreve uma pesquisa. Num segundo momento explicitaremos como a cartografia infantil se situa, potencialmente, no "estar-a-ser-criança", apresentando duas experiências cartográficas realizadas com crianças e jovens de Portugal e Brasil. Terminamos o texto com uma reflexão sobre como as cartografías infantis podem configurar-se com uma possibilidade de crianças e adultos abrirem mundo lado a lado.

palavras chave: cartografia infantil; infância; pesquisa; filosofia da diferença.

children's cartography: methodological approaches followed by experiences with children and adolescents from portugal and brazil

abstract

This article has a double objective that aims to situate, theoretically and empirically, children's cartography as a research methodology. In a first movement, we will situate children's cartography in its epistemological and philosophical bases, having as inspiration the cartographic conceptions of the philosophy of Deleuze \& Guattari and his commentators. The introduction of cartography with children shifts our research perspectives to include dimensions that were once imperceptible or relegated to a plane of lesser value: it maps, not just what children see, but what they say, and chronicles the coexistence of children and the world in ways not previously available to adult-organized research vehicles. We illustrate by chronicling two cartographic experiences carried out with children and young people from

\footnotetext{
${ }^{1}$ Projeto de pesquisa financiado pelo Conselho Nacional de Desenvolvimento Científico e Tecnológico - CNPq, no 445237/2014-7.

2 E-mail: tiagoa@eselx.ipl.pt

${ }^{3}$ Faculdade de Educação, Universidade São Paulo. Membro Integrado do Centro de Investigação em Educação do ISPA - Instituto Universitário com financiamento plurianual da Fundação para a Ciência e Tecnologia: UIDB/04853/2020.

${ }^{4}$ E-mail: bedin.costa@gmail.com
} 
cartografia infantil: enfoques metodológicos seguidos de experiências com crianças e jovens de portugal e brasil

Portugal and Brazil, and finish with a reflection on how researchers might configure mapping experiences that act to open the worlds of adults and children to each other.

keywords: children's cartography; childhood; research; philosophy of difference.

\section{cartografía infantil: enfoques metodológicos seguidos de experiencias con niños y jóvenes} de portugal y brasil

resumen

Este artículo tiene un doble objetivo que pretende situar, teórica y empíricamente, la cartografía infantil como metodología de investigación-intervención con niños pequeños. Situaremos, en un primer movimiento, la cartografía infantil en sus bases epistemológicas y filosóficas, teniendo como inspiración las concepciones cartográficas de la filosofía de Deleuze \& Guattari y sus comentaristas. La apuesta por una cartografía junto a las infancias desplaza la mirada y la acción de una investigación hacia dimensiones que antes eran imperceptibles o incluso relegadas a un plano de menor valor. En vez de sólo interesarse por lo que las infancias dicen, una cartografía infantil lanza su mapa sensible a las fuerzas entrelazadas en estos dichos, fuerzas que se revelan durante el proceso de convivencia de las infancias con el aparato humano e inhumano que circunscribe una investigación. En un segundo momento, explicaremos cómo se sitúa la cartografía infantil, potencialmente, en el "estar-a-ser-niño", presentando dos experiencias cartográficas realizadas con niños y jóvenes de Portugal y Brasil. Terminamos el texto con una reflexión sobre cómo se puede configurar la cartografía infantil con la posibilidad de que niños y adultos se abran al mundo uno al lado del otro.

palabras clave: cartografía infantil; infancia; investigación; filosofía de la diferencia. 
cartografia infantil: enfoques metodológicos seguidos de experiências com crianças e jovens de portugal e brasil

\title{
1. apresentação e enfoques metodológicos
}

1.1 quando "dar voz" às crianças já não basta

\begin{abstract}
Um dia eu vi um pesquisador positivista que fazia pesquisa sobre infância. Ele me pareceu tão importante. Um outro dia eu vi um pesquisador construtivista que pesquisava com crianças. Ele me pareceu tão útil. Um outro dia vi um pesquisador bem estranho e que era pesquisado por infâncias. Este eu juro de pé junto que era tolo, um pouco poeta. (Baierle et al., 2014).
\end{abstract}

Recentemente os estudos da criança e da infância têm incorporado um conjunto significativo de saberes e olhares (e.g. Burman, 2009; Davies, 2014; Sarmento, 2015; Sellers, 2013 Taylor, 2013; Weldemariam \& Wals, 2020) que desafiam as formas habituais de investigar com a infância. Num certo sentido, como Esser et al. (2016) referem, (re)conceptualizar a agência infantil, aqui entendida no contexto de uma contingência radical (Oswell, 2013, 2016; Prout, 2005) aberta a ontologias variáveis (Haraway, 1988) implica que sejamos capazes de nos relacionarmos com a infância a partir da sua contemporaneidade na e através da sua relação enquanto integrante do coletivo. No entanto, o coletivo a que nos referimos não é propriedade somente de humanos. Com o conceito de agência (Latour, 2005) evocamos o coletivo a partir da relação entre humanos e não humanos, cuja potência é, precisamente, afetar e ser afetado nas maneiras de "nos tornarmos com" (Haraway, 2007). Através de Camillis et al. (2016, p. 76), compreendemos a perspectiva que se abre a uma investigação quando esta incorpora elementos não humanos à análise, onde estes "deixam de ser apenas artefatos, cuja significação é atribuída pelo homem, e passam a ter agência, ou seja, participam das ações nas situações cotidianas e provocam transformações". $O$ mesmo é dizer que uma agência infantil deve ser entendida como algo que se constrói enquanto relação do aqui e agora com os modos de existência contingentes. Entender a agência infantil desta forma pressupõe que sejamos capazes de desenvolver processos relacionais nos quais já não basta "dar voz" às crianças, supostamente silenciadas, para formularem a sua perspetiva sobre a realidade, mas, antes, de acompanhar os 
cartografia infantil: enfoques metodológicos seguidos de experiências com crianças e jovens de portugal e brasil

processos através dos quais essa "voz" é construída numa "rede de atores" (Latour, 2005) e agenciamentos (Deleuze, 1968/2018). O que parece ser colocado em questão quando trabalhamos com tais noções é a romantização da própria noção de infância, uma infância que, devidamente "cuidada" por investigadores atentos, teria sempre algo a dizer de forma espontânea, pura e genuína. Neste sentido, conforme supracitado, não bastaria apenas "dar voz" a esta infância, dado que a própria voz, em processos investigativos, é sempre constituída de maneira relacional, no modo como os sujeitos se posicionam e são posicionados nos territórios dos quais fazem parte (através de seus artefatos) e com os quais interagem em todos os momentos de uma prática investigativa. Contudo, afirmar que "dar voz às crianças já não basta" não quer dizer que tenhamos que ignorar o que dizem as crianças. O que propomos é uma atenção voltada não somente ao que dizem os pequenos, mas em que circunstâncias estes podem ou não dizer, circunstâncias construídas ao longo do processo investigativo, exigindo-nos uma sensibilidade crítica diante dos agenciamentos que tornam possíveis estas mesmas falas. Ao invés de algo que possa ou precise ser afirmado, conforme Prout (2005, p. 65), a agência infantil se revela como uma coisa a ser investigada e permanentemente explorada (Prout, 2005, p. 65). A problemática é, então, considerar como é que a agência infantil pode ser construída dentro e através de uma grande variedade de dispositivos, materialidades e tecnologias, entre outros elementos sencientes. Perguntar por tal agência é perguntar pelo plano sobre o qual ela se assenta e pela maquinaria que a movimenta. Trata-se de um duplo movimento interpelante: da mesma forma em que interpelamos e somos interpelados pelos territórios sócio-culturais em que as crianças vivem, interpelamos e somos interpelados por toda a maquinaria discursiva e não discursiva que age e agencia as infâncias nestes mesmos territórios.

\section{2. cartografia: mirar o coletivo}

A pesquisa cartográfica em ciências humanas e sociais situa-se num movimento que procura dar corpo a outras formas de pensar a investigação nestes domínios (Teti e Filho, 2013; Cintra et al; 2017). Faz-se necessário ressaltar a importância de autoras e autores como Rolnik (1989), Fonseca e Kirst (2003), Passos, Kastrup e Escóssia (2009) 
e Passos, Kastrup e Tedesco (2014), publicando obras que possibilitaram a abertura a pesquisas de cunho cartográfico no contexto do Brasil e América Latina. A cartografia emerge, pois, no interior das perspectivas pós-estruturalistas e tem, à semelhança de outras metodologias que lhe são próximas, situar o trabalho de investigação como composição operada a partir da inseparabilidade entre sujeito e objeto, bem como da teoria e prática. O que isto implica é o reconhecimento de que o ato de investigar não é asséptico e, como tal, envolve múltiplas subjetividades que se afetam e se relacionam durante todo o processo investigativo.

Se formos entender a cartografia enquanto metodologia, precisamos pensar nas perguntas que ela pode nos ajudar a oferecer. Ao invés de perguntar pela essência das coisas, o cartógrafo pergunta pelo seu encontro com as coisas durante sua pesquisa. No lugar de o que é isto que vejo? (pergunta que remete ao mundo das essências), um como eu estou compondo com isto que vejo? Este segundo tipo de pergunta nos direciona ao processo, entendendo o cartógrafo enquanto criador de realidade, um compositor, aquele que com/põe na medida em que cartografa. (Costa, 2014, p. 70).

Com a cartografia reconhecemos que toda a investigação é potencialmente transformadora enquanto processo, quer de quem investiga quer do que ou quem dela participa. A cartografia opera a partir de um exercício ativo onde as identidades (de sujeito e objeto; pesquisador e pesquisado; adulto e criança) operam umas sobre as outras, por vezes embaralhando lugares culturalmente ossificados e colocados em oposição. De um modo geral, de acordo com Costa (2014, p. 67), mais do que uma metodologia científica, a cartografia aqui é entendida enquanto uma prática ou pragmática de pesquisa. A ideia de pragmática estaria ligada a um exercício ativo de operação sobre o mundo, não somente de verificação, levantamento ou interpretação de dados. Os saberes construídos em uma prática cartográfica passam a ser resultados desse encontro ético, das transformações e afetações que se operam entre as identidades, como também entre humanos e não humanos.

Inspirada no trabalho de Deleuze e Guattari (Deleuze \& Guattari, 2007), a investigação cartográfica tem já apresenta um significativo corpo crítico (Masny, 2013; Sellers, 2013), assumindo-se como uma metodologia de investigação-intervenção participativa (Paulon, \& Romagnoli, 2010) que discute a "inseparabilidade entre 
cartografia infantil: enfoques metodológicos seguidos de experiências com crianças e jovens de portugal e brasil

conhecer e fazer, entre pesquisar e intervir" (Passos, Kastrup, Escóssia, 2009, p. 7). Assim, em sintonia com a ideia de coletivo (Latour, 2004/2019), trata-se de uma estratégia metodológica que "mergulha na experiência que agencia sujeito e objeto, teoria e prática, num mesmo plano de produção ou de coemergência". Assim, investigar deixa de ser o gesto pelo qual se procura apenas a representação de um objeto, para se assumir como um processo pelo qual a realidade se transforma, obrigando-nos a forçar os limites dos nossos procedimentos metodológicos.

Entende-se que, ao propor como direção de pesquisa o acompanhamento de processos de produção de subjetividades e de mundos, a pesquisa cartográfica estaria mais próxima ao plano de forças que torna esta produção possível. Depreende-se daí sua dimensão mais revolucionária. Na medida em que o ato de pesquisar está necessariamente atrelado ao ato de intervir na realidade investigada, a cartografia visa a potencialização do plano comum participativo, engajando-se na construção ativa de um mundo no qual os processos de diferenciação possam ter lugar e espaço de expansão. Compromete-se, portanto, com a sustentação de um multiverso (James, 1895; Latour, 2004) no qual no one is left behind, mas mais do que isso - um multiverso no qual a capacidade de diferenciação que caracteriza todo e qualquer ser vivente possa ganhar jusante. No campo das perguntas, uma pesquisa cartográfica não se compromete com interpelações ontológicas do tipo "o que é?" (no caso deste artigo, com "o que é a infância?"), passando a se ocupar com seu vir-a-ser, com "o que pode esta infância" no agenciamento de pesquisa a ela oferecido.

\section{3. cartografia infantil e suas implicações na pesquisa}

A transposição dos procedimentos cartográficos ao trabalho com crianças proporcionou a criação do que Bandeira \& Costa (2011; 2012; 2013) chamaram de "cartografias infantis", terminologia que dá título a este texto e que inspirou a proposição das experiências que serão posteriormente narradas. A noção surge pela primeira vez através do projeto "Cartografias Infantis: a cidade pela criança, a fotografia pela infância", desenvolvido no Brasil entre 2010 e 2013 pela Universidade Federal do Rio do Sul - UFRGS e financiado pela Fundação Nacional das Artes (Funarte), órgão do governo federal brasileiro cuja missão é promover e incentivar a 
produção, a prática, o desenvolvimento e a difusão das artes no país. O nome dado ao projeto foi resultante da escolha pela prática de um olhar cartográfico, o qual se propunha apresentar a cidade de Porto Alegre (Brasil) a partir da multiplicidade de narrativas, registros fotográficos, escritas e desenhos de crianças que as habitavam (Bandeira \& Costa, 2013). Ao longo de três anos, crianças de diferentes idades e realidades sociais foram convidadas a participar de oficinas em que o deslocamento pela cidade se fazia presente, registando os seus encontros de forma visual e escrita. $\mathrm{O}$ propósito do projeto era promover uma investigação-intervenção “com" as crianças, e não somente "para" ou "sobre" as crianças na cidade. A distinção entre as preposições "para", "sobre" e "com" é mais do que gramatical, na medida em que situam o pesquisar com crianças em duas posições éticas distintas. À contrapelo do que historicamente se produz e se produziu em pesquisas no campo das infâncias, em que os pesquisadores projetam e desenvolvem ações "para" e "sobre" as crianças, situando-as à condição de objetos de pesquisa, o pesquisar "com" as crianças, na direção assumida pelo método da cartografia, redimensiona os papéis dos atores envolvidos em uma outra lógica de participação. De acordo com Sanchez (apud Fernandes, 2019, s/p), “Quando você diz que algo é 'para', é direcionado, feito para alguém. Já quando dizemos 'com', existe a dimensão do fazer junto, de não levar algo pronto a alguém, e sim construir a proposta no próprio fazer. Essa é a diferença conceitual de quem atua nesse campo".

Desse modo, o deslocamento do lugar de objetificação ocupado pela criança requer ainda uma ampliação do próprio conceito de participação, visando incluir neste expressões mais subtis. A participação não corresponde somente ao acolhimento das crianças em suas presenças visíveis, ou à inclusão de suas intenções e interesses. Tratase da participação em um plano comum de afetações, que exige não só o envolvimento formal dos sujeitos que participam, mas um exercício conjunto de acolhimento dos afectos que surgem no encontro com o outro. $\mathrm{O}$ trabalho na dimensão dos afetos se aproxima do que Farina e Rodrigues (2009) chamam de “cartografias do sensível”, de processos investigativos que lançam um olhar atento ao plano estético referente aos processos de transformação das formas e forças envolvidas. A aposta em uma cartografia do sensível junto às crianças desloca o olhar e o agir de uma pesquisa às 
cartografia infantil: enfoques metodológicos seguidos de experiências com crianças e jovens de portugal e brasil

dimensões e zonas outrora imperceptíveis ou mesmo relegadas a um plano de menor valia. Ao invés de somente se interessar pelo que as crianças dizem (interesse voltado à dimensão das formas, dado que o dizer ainda se situaria na dimensão do discurso), uma cartografia infantil lança seu mapa sensível às forças que estão imbricadas nestes dizeres, forças que se revelam durante o processo de convivência das crianças com todo o aparato humano e inumano que circunscreve a pesquisa. Por exemplo, ao trabalhar com narrativas, uma cartografia infantil procura também observar a relação que as crianças possuem com o sistema de prescrições e proscrições que envolve a língua, tomando como sua a advertência de Barthes (1978/2007), de que a língua seria fascista, não porque ela impediria de dizer, mas pelo fato de obrigar a dizer de uma determinada forma. O mesmo valeria para a produção de materiais audiovisuais junto às crianças (fotografias, desenhos, vídeos etc), também considerados não somente pelo que dão a ver, mas por todo um campo de forças que destes se desprende e com os quais o espectador - adulto ou não - irá se encontrar. Ao trabalhar com fotografias na dimensão cartográfica, Wunter (2016, p.27) utiliza o termo "partilha íntima" para designar o encontro das imagens com seus produtores (no caso, as crianças), partilha estabelecida sobretudo no silêncio das imagens desligadas da necessidade de representar o mundo vivido ou visto. "As imagens não mais capturam, mas projetam novas luzes ao mundo", escreve Wunder (2016, p. 30), situando as imagens como movimentadoras do pensar.

Dessa forma, ampliam-se sobremaneira as formas e possibilidades de participação das crianças na medida em que são convidadas às dimensões mais subtis do exercício participativo, presentes tanto no plano intelectual do pensamento, como no plano afectivo e imaginativo. Neste seguimento, mais do que observar um objeto estático (uma cidade, uma escola ou um espaço qualquer), a cartografia infantil caracteriza-se por acompanhar os movimentos, encontros e relações entre as crianças e o coletivo humano e não-humano envolvido. As cartografias infantis residem no acompanhamento de processos através dos quais as crianças se movimentam, afetam, se relacionam e se encontram com o mundo, e não na forma como as crianças representam esses mesmos objetos do mundo. Trata-se de um processo de acompanhamento dos deslocamentos (em si e nos outros) que os encontros das 
crianças agenciadas ao coletivo produzem. O referencial cartográfico não ignora, mas não toma como preocupação primeira legitimar a inserção das crianças no mundo, ou até as suas representações sobre o mundo. A aposta de uma cartografia infantil estaria em pousar seu olhar aos encontros das crianças com o mundo, nas estratégias que constroem não somente para assimilar este mundo, como também para oferecer-lhe sentidos outros.

Tal como Barros e Kastrup (2013) referem, as cartografias procuram desestabilizar as fronteiras entre pesquisador e campo, para que nessa passagem possam emergir focos de invenção, de alteridade. Neste caso, a cartografia infantil é entendida como um processo através do qual as crianças podem criar e propor outros mundos possíveis e sem condicionantes a priori, visto que, o conhecimento surge do fazer, do "estar-a-ser-criança" no mundo (Almeida, 2018a; Almeida, 2018b). Paralelamente, as cartografias infantis são uma oportunidade de investigar outras relações que não apenas as que são mediadas pela voz. No fundo, esta metodologia configura, por um lado, uma oportunidade de introduzir outras linguagens e aparelhos a partir dos quais as crianças descrevem e apresentam as suas vivências (Oswell, 2013) e visões sobre o mundo (Ärlemalm-Hagsér \& Davis, 2014) e, por outro, uma forma de acompanhar o processo de subjetivação e de inventividade associados aos deslocamentos das crianças pelos territórios dos quais fazem parte.

\section{4. cartografando com outras escalas}

Na ciência cartográfica, quando se projeta um mapa é preciso informar a escala com a qual se está trabalhando, em quantas vezes o território a ser cartografado foi reduzido. A cartografia, nesta perspectiva, mantém uma relação estreita com os pressupostos geográficos. No caso de uma cartografia infantil, o que se propõe é uma geografia assumida a partir dos encontros das crianças com os territórios, e dos afetos que se desprendem a partir destes encontros. A escala, ao invés de geográfica, tornase afetiva, embaralhando os códigos comuns e inserindo outras linhas às segmentaridades pré-estabelecidas. Falamos então de uma experiência cartográfica que ganha força quando inserida em uma dimensão coletiva, onde as próprias crianças têm a oportunidade de compartilhar seus encontros com os múltiplos territórios de 
cartografia infantil: enfoques metodológicos seguidos de experiências com crianças e jovens de portugal e brasil

uma cidade, pluralizando a própria noção de cartografia (Oliveira \& Paraíso, 2012). Um parque, por exemplo, sob a percepção infantil pode ser muito mais do que um parque. Uma escola pode se abrir a diversos outros espaços quando sensibilizada pela presença das crianças. O mesmo para os espaços políticos, de saúde, assistenciais etc. Trata-se da inserção de outras linhas aos mapas já estabelecidos, inusitadas escalas de propagação e contágio, mapas de lugares, percursos e deslocamentos multiplicados pelas narrativas das crianças que partilham destes espaços. Nesta relação entre infância, pesquisa e cidade, destacamos a organização dos dossiês Infâncias na cidade: um diálogo com a Educação (Santos, 2018), Crianças e suas infâncias na cidade (Araújo, Moreira e Fernandes, 2019) e Perspectivas para pensar as cidades: infâncias, educação, democracia e justiça (Gobi e Anjos, 2020), publicações que têm contribuido na problematização dos limites e potencialidades de um trabalho com as infâncias. Quando propomos a crianças e jovens que desenvolvam processos cartográficos é essencial que crianças e adultos partilhem dispositivos operativos como, por exemplo, diários de campo ou registos audiovisuais. Ao trabalhar com crianças e jovens, o registo do processo é fundamental pelo que, segundo Barros e Kastrup (2009), essas anotações estarão não só na base do conhecimento produzido, como também serão essenciais para a intervenção e para a ação política que advém da investigaçãointervenção infantil. No caso das crianças pequenas, cabe ao adulto registar os deslocamentos infantis sobre o território e, também, apresentar disponibilidade para a qualquer altura mudar o rumo da investigação consoante aquilo que observa e registra no contato com as mesmas. Já no caso das crianças maiores e jovens, estes podem, individual e coletivamente, assumir o lugar de narradores e com isso analisar os seus próprios deslocamentos ao longo do processo. Cabe a crianças e adultos, através da ética relacional, afirmar uma voz infantil capaz de questionar, problematizar e agir no coletivo. Numa cartografia leva-se em conta o potencial infantil que há em toda a linguagem, de uma infância que não se reduz a uma faixa etária do desenvolvimento humano, e que pode ser acionada em sua potência de involução das formas e signos institucionalizados. 
A infância garatuja signos. É o balbucio possível a tudo que designa, a toda vontade de indicar, apontar, marcar e mostrar, o agente designador de contraefetuações históricas. Em vez de catar ou de fazer uso de signos disponíveis, a infância os alquimiza em nome de certa magia. Ela não toca o mundo, mas aquilo com o qual se crê tocar o mundo, ou seja, a linguagem. (Costa \& Bandeira, 2017, p. 288).

Ao investirem no potencial infantil da linguagem, adultos e também crianças devem estar disponíveis a se reinventarem na arte da pergunta a partir da qual “coabitam no não saber" (Almeida \& Ó, 2020). Contudo, em uma cartografia infantil a pergunta não deve ser propriedade de um adulto e, enquanto tal, direcionada às crianças. O trabalho cartográfico busca a construção de perguntas conjuntas, construídas na relação dos sujeitos envolvidos e à necessidade dos encontros.

Assim, quando perguntamos algo a alguém, podemos ser portadores de uma dúvida. Mas quando nos perguntamos algo com alguém, é a dúvida que nos porta a algum lugar, que nos desloca do lugar que habitamos no pensamento e nos permite habitar outros locais... perdemos certo controle sobre nós mesmos... e ganhamos certas possibilidades e potências também para nós mesmos... (Kohan; Durán, 2017, p. 175).

Neste sentido, as cartografias em geral, e as infantis em particular, abrem um campo no qual não se pode controlar ou levantar grandes hipóteses, mas, através das perguntas construídas coletivamente, interrogar adultos e crianças, lado a lado, abrindo uma zona de possibilidades que só uma pesquisa que se faz ao caminhar pode nos proporcionar.

É sob este ponto de vista conceptual e metodológico que este texto procura problematizar e pensar as cartografías infantis enquanto possibilidade de abrir mundos com as crianças. Por abrir mundos entenda-se o gesto conjunto de explorar, questionar e relacionar, numa permanente vai e vem, vida e pensamento. Trata-se assim de propor a cartografia como um momento em que, tal como Serres nos diz, "a educação empurra para o exterior" no sentido em que "nenhuma aprendizagem evita a viagem" (1996, p. 23).

Com esse propósito, este texto partilha duas experiências, bastante diversas entre si, cujo eixo comum foi o mote de pensar a cartografia infantil enquanto viagem e processo de acompanhamento dos deslocamentos da infância pelo coletivo. Em ambas as experiências, o mote foi dado pela intenção de captar as formas como as 
cartografia infantil: enfoques metodológicos seguidos de experiências com crianças e jovens de portugal e brasil

crianças se deixavam afetar e, também, como e o que registavam nesse processo. Para tal mobilizaram metodologias visuais (Semenec \& Diaz-Diaz, 2020) no sentido de dar outras linguagens às crianças para partilharem e simbolizarem os seus afetos e pensamentos enquanto exploram e abrem outros mundos possíveis.

\section{2. experiências cartográficas em portugal e brasil}

\section{1. deslocamentos pelo coletivo em um jardim de infância}

Entre setembro de 2019 e março de 2020 convidou-se um grupo de 21 crianças com idades entre os 4 e os 5 anos e uma educadora de infância a iniciarem um processo cartográfico sobre os seus deslocamentos no espaço exterior da instituição que frequentavam. Trata-se de uma instituição Particular de Solidariedade Social situada em Lisboa, Portugal, destinada à Educação de Infância e a servir a comunidade local. Esta proposta surgiu no sentido de acompanhar como estas crianças se deixavam afetar e afetavam o coletivo que lhes era contingente. Ao longo do processo, o espaço exterior foi adotado, por crianças e adultos, como um espaço privilegiado para observar e partilhar experiências e múltiplas descobertas. Foi este o mote a partir do qual nos interrogámos sobre quais os deslocamentos que o encontro entre criançasadulto-exterior provocariam. Desde logo, as nossas questões desdobraram-se: para onde olhavam as crianças? O que alcançava o seu campo de visão? Que outros mundos surgiriam através do olhar das crianças? A grande pergunta que colocámos em andamento foi, então, quais as transformações potenciadas pelo processo cartográfico?

O desafio que lançámos às crianças foi, precisamente, convidá-las a "olhar" o espaço exterior e que partilhassem as suas "visões" sobre o mesmo. Decidimos, em grupo, que os registos destas saídas de campo seriam através de fotografias por si tiradas. Foi desta forma que desafiámos as crianças a fotografar o espaço exterior e a iniciar o processo cartográfico sobre que "visões" tinham do exterior da instituição. Interessava aqui, mais do que dirigir ou condicionar o "olhar" das crianças sobre a sua relação com o espaço exterior, compreender com elas de que forma as suas incursões pelo espaço exterior produziam um duplo gesto. $O$ gesto de perguntar a partir da sua experiência e o gesto de projetar, sonhar outros mundos possíveis. Como dispositivo operativo do processo cartográfico escolhemos as imagens fotografadas pelas crianças 
e o registo diário das suas interações. Encontrámos na fluidez do processo, no acompanhar das incursões das crianças e na sua escuta uma potência transformadora de todos os envolvidos: crianças-adultos-exterior.

Rapidamente se compreendeu que a linguagem digital aqui convocada possibilitava convocar o "momento" captado para incitar a discussão do grupo sobre as várias visões possíveis de tecer a partir de um mesmo momento. A relação com os artefatos fotográficos - com os tais operadores não humanos apontados por Latour (2005) - permitiu ao coletivo crianças-professora-pesquisador operar em um plano de visibilidades tratado enquanto força, dado que as imagens produzidas não só mostravam os encontros, como convidavam a outros encontros.

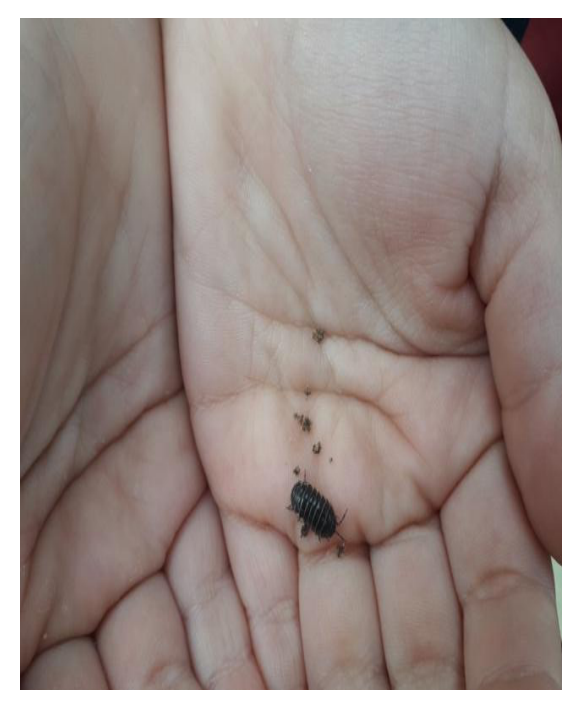

Fig.1. Foto tirada por A. a um bicho de conta apanhado por C.

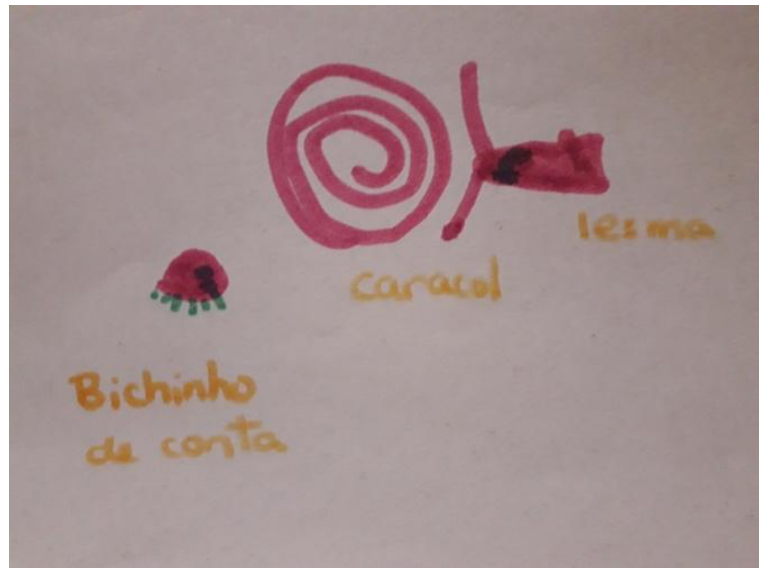

Fig. 2. Desenho realizado por G. na sequência das saídas de campo. 
cartografia infantil: enfoques metodológicos seguidos de experiências com crianças e jovens de portugal e brasil

Muitas das observações e verbalizações que iam surgindo, numa manifesta vontade de estar mais tempo "lá fora", desafiaram os adultos a um outro "olhar" sobre os usos do espaço exterior. Emergia, a partir dos deslocamentos pelo exterior das crianças, a necessidade de uma escuta atenta e cuidada, assim como uma atitude de valorização das iniciativas infantis. Foram o interesse e os deslocamentos das crianças, as suas questões e o encontro entre contemporaneidades que motivaram, ainda mais, crianças e adultos a refletir sobre este espaço. Houve qualquer coisa no deslocamento e no questionamento das crianças sobre o exterior e sobre a sua relação com o não humano que despertaram, num primeiro momento, a reflexibilidade sobre o instituído, sobre o não refletido e sobre o naturalizado na ação educativa: que outro espaço exterior podíamos, afinal, construir eticamente e em relação com as crianças a partir dos seus deslocamentos?

O exterior era agora, por ação política das crianças, decorrente da sua pesquisaintervenção, reconfigurado e essa é a potência do processo cartográfico quando acompanhado pela disponibilidade de escutarmos as crianças (Davies, 2014). Não se trata de oferecer soluções já antigas, mas de acompanhar o espanto infantil no seu "estar-a-ser-criança" (Almeida, 2018a; 2019). O mesmo é dizer que é na contemporaneidade, na contingência da experiência que construímos uma ação política com a potência de agir no coletivo. O espaço exterior transformava-se, reconfigurava-se, aos poucos, num espaço aberto à inventividade.

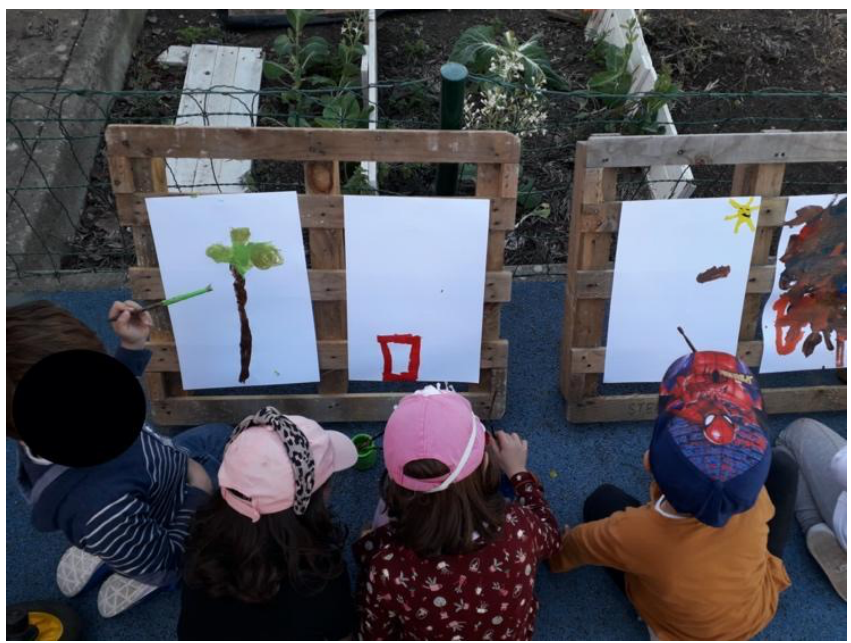

Fig.3. Fotografia ilustrativa de um outro uso proposto pelas crianças para o tempo no exterior. 


\section{2. cartografia da língua em um dicionário das infâncias}

Ao longo de 2016 e 2017, um coletivo de pesquisadores da Universidade Federal do Rio Grande do Sul e docentes de escolas públicas brasileiras se reuniu em torno de um projeto bastante singular: a construção de um dicionário protagonizado por estudantes. A proposta inicial foi inspirada no trabalho realizado pelo professor Javier Naranjo, onde passou 10 anos recolhendo verbetes de diversas escolas do estado de Antioquía, região rural do leste da Colômbia, publicado em "Casa de las estrellas: el universo contado por los niños" (Naranjo, 2009). A ideia de realizar um trabalho de cartografia infantil tendo como horizonte a publicação de um dicionário nos parecia desafiadora. Ao longo de dois anos, 450 estudantes se envolveram na construção de 650 verbetes acerca de temas diversos, compilados no livro Estátuas de Nuvens: dicionário de palavras pesquisadas por infâncias (Costa et al., 2017). A questão que se colocou desde o início de nossa cartografia foi a de apostar em uma infância da língua (Barros, 2008), tendo como parceiro(a)s estudantes das mais diferentes idades e instituições. Encontramos em Kohan (2015) uma definição de infância que nos parecia bastante amigável, dado que, ao ser colocada ao lado do mistério, produzia uma certa recusa a situar os sujeitos em um determinado espaço-tempo da vida.

A infância, devemos dizê-lo claramente desde o início, é um mistério, um enigma, uma pergunta. Não me refiro, claro está, apenas a uma etapa cronológica da vida humana, mas antes que qualquer outra coisa, a essa condição que nos habita - às vezes de forma mais perceptível, às vezes quase imperceptível - desde que habitamos o mundo. Essa condição que, também devemos dizê-lo desde o começo, não nos abandona, mesmo na forma do silêncio ou de uma presença imperceptível, até que abandonamos o mundo. (Kohan, 2015, p. 217).

Ao assumirmos a infância como condição que habita a todos, interessava-nos lançar nossos mapas às regiões inusitadas e imperceptíveis do pensamento e da linguagem. No entanto, a aposta em uma ética cartográfica nos colocava diante de perguntas sobre as quais não tínhamos respostas prontas: como construir partilhas íntimas com os 450 participantes da pesquisa, de modo que pudéssemos criar condições para que experiências de linguagem e pensamento pudessem se fazer presentes? De que modo poderíamos sustentar a ideia do coletivo, não sufocando com 
cartografia infantil: enfoques metodológicos seguidos de experiências com crianças e jovens de portugal e brasil

isso a potência singular das identidades envolvidas? Como garantir que o processo de produção dos verbetes pudesse ser tão ou mais relevante que o seu produto final?

Foi com estas perguntas que convidamos 17 professora(e)s a embarcar em nossa viagem, iniciando o trabalho junto a estudantes infantes dos 2 aos 95 anos de idade. Cada professor(a) foi instigado(a) a compor coletivos de trabalho em suas respectivas instituições, lançando o convite a estudantes que porventura se interessassem. Chegamos então a 15 coletivos, cada qual com realidades bastante singulares. Fizeram parte do trabalho coletivos vinculados ao jardim de infância, escolas de ensino fundamental, escola indígena, escola para alunos surdos, escola preparatórias para o trabalho, escola para jovens e adultos e universidade. A combinação foi a de que cada um dos 15 coletivos criasse um nome para si, passando a assinar coletivamente os verbetes por estes produzidos. Como se tratava de realidades diversas, optamos pela autonomia de cada grupo em relação aos seus processos de condução e produção dos verbetes. Contudo, uma condição deveria ser respeitada: que nossa cartografia tivesse como mirada o prazer e a ludicidade.

Durante o processo de preparo, fiquei muito animada, estava curiosa para saber como eles iriam expor suas ideias, entendimentos e pontos de vista. Fomos ao pátio aproveitar o bom tempo, cheiro de mato, barulho dos pássaros, sentir o vento. Eles valorizam os sentidos. Sentamo-nos em círculo e usamos uma bola como objeto da palavra, que passou de mão em mão; muitas vezes fui lançando as palavras e as definições surgiam de forma livre, profunda e divertida. Por inúmeras vezes nos víamos rindo, não da resposta de um ou de outro, mas ríamos da alegria de poder nos divertir uns com os outros. (Silva, 2017, p.236).

O relato desta professora-cartógrafa traz a dimensão lúdica a que nos referimos, uma ludicidade carregada de surpresas diante do que pode o coletivo quando se põe a cartografar junto. Também percebemos no relato a presença do território e a rede de sensações por ele disparado. O processo de construção dos verbetes veio acompanhado do clima, do cheiro, do barulho e do vento. "Em vez de referenciais teóricos, os 650 verbetes deste dicionário perguntam por referenciais terrestres" (Costa et al., 2017, p. 24). A pergunta por "referenciais terrestres" diz respeito a uma aposta na relação dos coletivos com seus respectivos territórios, com os elementos humanos e também não humanos que destes fazem parte. A aposta também se deu em relação 
às palavras cartografadas de modo imanente, na relação da infância com o espaço e no confronto com uma língua maior, esta carregada de decalques e palavras de ordem. Uma cartografia das palavras pesquisadas por infâncias necessitava, a nosso ver, de operações capazes de produzir linhas de fuga à lógica adultocêntrica que rege o universo da linguagem, um combate lúdico ao "adultocentrismo que silencia, apaga e flagela" (Abramovay, 2019). Dito de outra forma, mas não menos crítica, é a definição que um coletivo composto por crianças de 6 a 8 anos deu para a palavra adulto, relacionando-a diretamente a um exercício vulgar de poder: “Adulto: ser grande é mandar" (Coletivo Turma do Aprender, 2017a, p.32).

Ao invés das crianças pesquisarem as palavras, nossa cartografia se interessava pelas palavras sendo pesquisadas por infâncias. Essa torção não nos parecia meramente retórica, uma vez que, conforme supracitado no início deste artigo, não se tratava de "dar voz às crianças", mas de, no trabalho com a língua adultocentrada, escová-la com cerdas infantis. Encontramos no poeta Manoel de Barros uma assertiva que nos encheu de coragem: "as palavras possuem no corpo oralidades remontadas e muitas significâncias. Eu queria então escovar as palavras para escutar o primeiro engasgar de cada uma" (Barros, 2008, p. 21). Na orelha do nosso dicionário, assinada pela professora Rosana Fernandes, as palavras escovadas encontram verbos como pensar, criar, perguntar, duvidar, descascar, furar, silenciar, brincar, escutar, suspirar e hesitar.

Um livro que propõe um longo exercício de pensar e criar, perguntar e duvidar das definições e da definição de definição. Os verbetes descascaram as palavras, tiraram camadas que saturam e pesam. Furaram as palavras, deixaram entrar um ar fresco, fizeram silêncio, deixaram as palavras brincar e escutaram os tropeços, os suspiros, as hesitações. (Fernandes, 2017, p. 24).

No entanto, mesmo que lúdica, a conjugação cartográfica destes verbos se torna um gesto ético-político, uma vez que se trata de escovar as palavras para habitar um outro ethos na relação com as diferenças, uma habitação que se faz em disputa e nem sempre com as melhores armas. Vasculhando nosso dicionário, encontramos no verbete "palavra" duas definições que performatizam a tensão que há neste território de disputa representado pela linguagem. Diante da dimensão fascista da 
cartografia infantil: enfoques metodológicos seguidos de experiências com crianças e jovens de portugal e brasil

língua (Barthes, 1978/2007), a qual não nos proíbe, mas nos obriga a dizer de determinada forma, não é de se surpreender que a definição de "palavra" encontre em nosso dicionário de infâncias significantes relacionados à guerra, tristeza e morte. Considerando os clichês de infância, geralmente ligados às ideias de pureza e espontaneidade, talvez fosse mais esperado considerar que as definições para "palavra" tivessem um caráter de encantamento. No entanto, por trabalharmos com os tais "referenciais terrestres", e considerando que múltiplas são as infâncias (ainda mais no contexto latinoamericano, em que a desigualdade social se apresenta como um dado primordial), chegamos a duas definições que não se conformam a modelos ideais. De acordo com um coletivo composto por crianças de 6 a 8 anos, "palavra é quando uma pessoa fala e a outra não pode falar. Às vezes se fala, às vezes se escreve. Uma palavra faz as pessoas ficarem tristes... morrer" (Coletivo Clube Secreto das Letras, 2017, p. 157). Já um coletivo composto por estudantes universitários traz a seguinte definição: "Palavra: primeira arma sacada em uma guerra ou conflito. Unidade morfológica ou fonológica capaz de destruir impérios e nações" (Coletivo Fomabidanleh, 2017, p. 157).

$\mathrm{Na}$ esteira dos verbetes que nos fazem pensar desde uma criticidade mais profunda, encontramos o de "infância", produzido por um coletivo de idosos em etapa de alfabetização: “Infância: muito importante, é longa. 'É isso que eu não tive' (...)" (Coletivo Esperança, 2017, p. 122). Quando lemos que a infância pode ser "isso que não se teve", somos forçosamente convocados a olhar as múltiplas infâncias que habitam o mundo, e a violência que acabamos por perpetuar quando tomamos como único o modelo de infância enquanto algo idílico, bonito e irretocável.

Mas da mesma forma que encontramos densos verbetes, somos também surpreendidos por palavras críticas mexidas desde sua simplicidade. "Humano: é uma pessoa que não é um robô, tem pele e tem sangue" (Coletivo Turma do Aprender, 2017b, p. 157). Neste verbete, assinado por crianças de 6 a 8 anos, percebemos a escovação da palavra humano, uma vez que a coloca diante de um condicionante ético nada desprezível: para que consigamos exercer nossa humanidade é preciso não sermos apenas um robô (em tempos onde a robotização dos modos de vida parece ser uma das nossas maiores características, não ser mais um robô é um exercício ético que 
nos exige bastante engajamento). Diante da mecanização da vida, e da dívida que a ela parecemos sempre prestar, lembramos de um breve e provocador verbete produzido por estudantes universitários: “Relógio: dispositivo que mostra o quão atrasado você está" (Coletivo Fomabidanleh, 2017, p.195). Nessa linha de pensamento é também muito interessante o verbete cunhado por estudantes de 8 a 10 anos: “Trabalho: é coisa de adulto, deixa as pessoas cansadas" (Coletivo Estudantes Americano, 2017, p.208). Apesar de simples, ou melhor, por serem justamente simples, estes verbetes lançam perguntas éticas a um mundo que talvez não saiba mais reconhecê-las como suas.

Para finalizar, trazemos o verbete "casa", produzido por crianças de 2 a 5 anos: "uma casa é para a gente entrar nela" (Coletivo Descendentes, 2017, p. 48). O que percebemos na aparente ingenuidade da definição é a escovação da ideia da casa enquanto propriedade privada, passando a ser um convite à entrada do outro. Ora, uma casa é para entrar, não para se ter. Esta bonita imagem traduz o que aqui pensamos por cartografia infantil: a construção de mapas/moradas coletivas que, ao invés de circunscrevem realidades particulares fechadas, operam como um convite ao outro, seja este uma pessoa, uma sensação, um afeto, uma palavra, uma imagem... Através da poesia de Manoel de Barros e de um coletivo de estudantes universitários lembramos que, para construirmos nossas casas, faz-se mister que sejamos bons leitores da "gramática expositiva do chão" (Barros, 1969/2010), sendo o chão "aquilo que não nos deixa cair para dentro da Terra" (Coletivo MDC da Psiquê, 2017, p.49). Os mapas de nossas cartografias nos levam a experimentar um chão que nos seja mais amigável, para que não sejamos tragados para dentro das demandas de um mundo adultocêntrico e robotizado, este que nos incita (adultos e crianças que somos) a recalcar o que talvez tenhamos de mais precioso, que é a nossa humanidade.

\section{3. em jeito de conclusão}

O que aqui se pretende expressar é a potência da cartografia enquanto atitude ética de crianças e adultos habitarem em simultâneo o desconhecido (Almeida \& Ó, 2020). Em ambas as experiências, crianças desafiaram adultos e adultos desafiaram crianças. Maravilhámo-nos e abrimo-nos ao espanto, em grupo, com o simples e investigámos o que se nos oferecia como desconhecido. Em conjunto, e através dos 
cartografia infantil: enfoques metodológicos seguidos de experiências com crianças e jovens de portugal e brasil

processos desencadeados pelas crianças construímos outras narrativas, quer através da imagem, quer por meio da língua, em que crianças e adultos se deixaram afetar e afetaram mediante a potência que encontros inesperados promoveram na ressignificação de si. Trata-se de um tempo e de um espaço em que o contexto educativo dá e abre o mundo à experiência infantil. Por último, podemos referir que todos estes processos implicam uma visão de criança como sujeito em devir e em permanente relação com os elementos humanos e não humanos da sua comunidade.

O instante atual não sendo um instante de ser ou de presente "no sentido estrito", sendo o instante que passa, força-nos a pensar o devir, e a pensá-lo precisamente como o que não pôde começar e o que não pode terminar de tornar-se. Como pensamento do puro devir funda o eterno retorno? Basta esse pensamento para parar de crer no ser distinto do devir, oposto ao devir; mas basta também esse pensamento para crer no ser do próprio devir (Deleuze, 1968/2018, p. 65).

Será, então, numa comunidade situada dentro de um mundo aglomerado onde as crianças são afetadas por múltiplos atores, que se inventa e reinventa modos de ser. Como nos diz Serres “o fôlego inventivo resulta somente da vida porque a vida inventa" (1996, p. 99). Só através de uma ética relacional que privilegia uma educação multiversa, culturalmente situada e cooperada, podemos libertar a infância do seu terrível destino de tornar-se, sempre e eternamente, o adulto por vir, e possibilitar oportunidades para uma existência inventiva no seu "estar-a-ser-criança". Uma existencia que que contribua para a constituição de si e para a criação de outros mundos possíveis.

Agradecimento: um especial agradecimento a todas as crianças, jovens e adultos sem as quais não seria possível escrever este texto. A sua participação nos processos cartográficos foi o motor do "deslocamento de si" dos próprios pesquisadores. Muito obrigado.

\section{referências}

Abramovay, M. (2019). O adultocentrismo que silencia, apaga e flagela o jovem. Revista do Instituto Humanitas Unisinos, São Leopoldo, edição 593. Disponível em: http://www.ihuonline.unisinos.br/artigo/7570-o-adultocentrismo-que-silenciaapaga-e-flagela-o-jovem.

Almeida, T. (2018a). O governo da infância: o brincar como técnica de si. Arquivos Brasileiros de Psicologia, 70, spe, p. 152-166. 
Almeida, T. (2018b). Currículos e agenciamentos do devir: trânsitos ao redor de Deleuze na delimitação da infância a partir de Emílio de Rousseau. FRACTAL Revista de Psicologia, 30, 3, p. 302-309 doi: https://doi.org/10.22409/1984-0292/v30i3/9582

Almeida, T. (2019). Psicologia do desenvolvimento e a delimitação de modos de ser criança. Devir-adulto, devir-sujeito e a educação de infância. In. F. Lemos, M. L. Nascimento (org.), Biopolítica e Tanatopolítica: A Agonística dos Processos de Subjetivação Contemporâneos (pp. 229-249). Curitiba: Editora CRV.

Almeida, T., \& Ó, J. R. (2020). A vida como acontecimento e a potência do indeterminado em tempos de pandemia para pensar a relação com a infância. Revista Socidad e Infancias, 4, p. 185-188. Doi: 10.5209 / soci.69737

Ärlemalm-Hagsér, E., \& Davis, J. (2014). Examining the rhetoric: A comparison of how sustainability and young children's participation and agency are framed in Australian and Swedish early childhood education curricula. Contemporary Issues in Early Childhood September, 15(3), 231-244.

Baierle, A., Farina, G.., Fonseca, L. Costa, L.B. (2014). Cartografâncias: 20 notas sobre pesquisar e ser pesquisada por infâncias. Filosofía para niños. Revista Internacional de los Centros Iberoamericanos de Filosofía para Niños y Niñas y de Filosofía para Crianças, n.9, 2014, 101-108.

Bandeira, L.V. (2011). Cartografias Infantis: é possível olhar a cidade através do olhar da infância?. Monografia final de curso, Universidade Federal do Rio Grande do Sul, Porto Alegre, Brasil. Disponível em: http://www.bibliotecadigital.ufrgs.br/da.php?nrb=000817591\&loc $=2012 \& l=03 \mathrm{fb} 8 \mathrm{db} 372 \mathrm{adc} 1 \mathrm{~d}$ e

Bandeira, L.V. Costa, L.B. (2012). Cartografias infantis: reinventando a cidade com o olhar das crianças de uma comunidade quilombola urbana. Revista Infancia Latinoamericana. Espanha, n.3, 5863. https://www.rosasensat.org/files/a_cartografia_como_conceito_final13_10.pdf

Bandeira, L.V. Costa, L.B. (2013). Cartografias Infantis: a cidade pela criança, a fotografia pela infância. Arte Sesc, n. 13, 54-57. https://issuu.com/90406/docs/revista_arte_sesc_13

Barros, M. (1969/2010). Gramática expositiva do chão. São Paulo: Leya.

Barros, M. (2008). Memórias inventadas: as infâncias de Manoel de Barros. São Paulo: Editora Planeta do Brasil.

Barthes, R. (1978/2007). Aula: aula inaugural na cadeira de semiologia literária do Colégio de França, pronunciada dia 7 de janeiro de 1977. São Paulo: Cultrix.

Burman, E. (2009). Child, Images, Nation. London: Taylor \& Francis.

Camillis, P.K. Bussular, C.Z. Antonello, C.S. (2016). A agência a partir da Teoria Ator-Rede: reflexões e contribuições para as pesquisas em administração. Revista O\&S, Salvador, 23 (76), 73-96. Disponível em: https://www.scielo.br/pdf/osoc/v23n76/1413-585X-osoc-2376-0073.pdf

Cintra, A. et al. (2017). Cartografia nas pesquisas científicas: uma revisão integrativa. Fractal: Revista de Psicologia, v. 29, n. 1, p. 45-53, jan.-abr. 2017. https://www.scielo.br/pdf/fractal/v29n1/1984-0292-fractal-29-01-00045.pdf

Coletivo Clube Secreto das Letras. (2017). Olho (verbete). In: Costa, L.B. Bandeira, L.B. Corrêa, T.M. (orgs). Estátuas de Nuvens: dicionário de palavras pesquisadas por infâncias. Porto Alegre: Editora Sulina, 145.

Coletivo Clube Secreto das Letras. (2017). Palavra (verbete). In: In: Costa, L.B. Bandeira, L.B. Corrêa, T.M. (orgs). Estátuas de Nuvens: dicionário de palavras pesquisadas por infâncias. Porto Alegre: Editora Sulina, 157.

Coletivo Descendentes. (2017). Casa (verbete). In: Costa, L.B. Bandeira, L.B. Corrêa, T.M. (orgs). Estátuas de Nuvens: dicionário de palavras pesquisadas por infâncias. Porto Alegre: Editora Sulina, 48. 
cartografia infantil: enfoques metodológicos seguidos de experiências com crianças e jovens de portugal e brasil

Coletivo Esperança. (2017). Infância (verbete). In: Costa, L.B. Bandeira, L.B. Corrêa, T.M. (orgs). Estátuas de Nuvens: dicionário de palavras pesquisadas por infâncias. Porto Alegre: Editora Sulina, 122.

Coletivo Fomabidanleh. (2017). Palavra (verbete). In: Costa, L.B. Bandeira, L.B. Corrêa, T.M. (orgs). Estátuas de Nuvens: dicionário de palavras pesquisadas por infâncias. Porto Alegre: Editora Sulina, 157.

Coletivo Fomabidanleh. (2017). Relógio (verbete). In: Costa, L.B. Bandeira, L.B. Corrêa, T.M. (orgs). Estátuas de Nuvens: dicionário de palavras pesquisadas por infâncias. Porto Alegre: Editora Sulina, 195.

Coletivo MDC da Psiquê. (2017). Chão (verbete). In: Costa, L.B. Bandeira, L.B. Corrêa, T.M. (orgs). Estátuas de Nuvens: dicionário de palavras pesquisadas por infâncias. Porto Alegre: Editora Sulina, 49.

Coletivo Turma do Aprender. (2017a). Adulto (verbete). In: Costa, L.B. Bandeira, L.B. Corrêa, T.M. (orgs). Estátuas de Nuvens: dicionário de palavras pesquisadas por infâncias. Porto Alegre: Editora Sulina, p.32.

Coletivo Turma do Aprender. (2017b). In: Costa, L.B. Bandeira, L.B. Corrêa, T.M. (orgs). Estátuas de Nuvens: dicionário de palavras pesquisadas por infâncias. Porto Alegre: Editora Sulina, p. 120.

Costa, L.B. (2014). Cartografia: uma outra forma de pesquisar. Revista digital do LAV. Santa Maria, UFSM, Vol. 7, n. 2 (maio./ago. 2014), p. 65-76. Disponível em: http://www.bibliotecadigital.ufrgs.br/da.php?nrb=000935545\&loc $=2014 \& l=e 1 b 68 d 91$ de8b6a $7 \mathrm{e}$

Costa, L.B. Bandeira, L.B. Corrêa, T.M. (orgs). (2017). Estátuas de Nuvens: dicionário de palavras pesquisadas por infâncias. Porto Alegre: Editora SulinA.

Deleuze, G. (1962/2019). Nietzsche e a Filo sofia. São Paulo: Edicões N-1.

Deleuze, G. (1968/2018). A Lógica do Sentido. São Paulo: Perspectiva.

Deleuze, G., Guattari, F. (2007). Mil Planaltos: capitalismo e esquizofrenia. Lisboa: AssirioAlvim

Davies, B. (2014). Listening to Children [VitalSource Bookshelf version]. Retrieved from vbk:/ /9781317672258

Esser, F., Baader, M., Betz, T., \& Hugerland, B. (2016). Reconceptualising Agency and Childhood [VitalSource Bookshelf version]. Retrieved from vbk://9781317524403

Farina, C. Rodrigues, C. (2009). Cartografias do sensível: estética e subjetivação na contemporaneidade. Porto Alegre: Editora Evangraf.

Fernandes, R. (2017). Orelha do livro. In: Costa, L.B. Bandeira, L.B. Corrêa, T.M. (orgs). Estátuas de Nuvens: dicionário de palavras pesquisadas por infâncias. Porto Alegre: Editora Sulina.

Fernandes, F. (2019). Filosofia para ou com crianças: o que é e por que apostar nessa ideia. Multirio: a mídia educativa da cidade. Disponível em: http://multirio.rio.rj.gov.br/index.php/leia/reportagens-artigos/reportagens/15246-filosofiapara-ou-com-crian\%C3\%A7as-o-que-\%C3\%A9-e-por-que-apostar-nessa-ideia

Fonseca, T.; Kirst, P. (2003). Cartografias e devires: a construção do presente. Porto Alegre: UFRGS.

Gobbi, M. A., \& dos Anjos, C. I. (2020). Apresentação do Dossiê Temático: Perspectivas para pensar as cidades: infâncias, educação, democracia e justiça. Práxis Educacional, 16(40), 13-24. Disponível

em: https:// periodicos2.uesb.br/index.php/praxis/article/view/6986

Haraway, D. (1988). Situated Knowledges: The Science Question in Feminism and the Privilege of Partial Perspective, Feminist Studies, 14, 3, pp. 575-59

Haraway, D. (2007). When species meet. Minnesota: University of Minnesota Press. 
Kohan, W. O. (2015). Visões de filosofia: infância. Revista ALEA, Rio de Janeiro, vol. 17 (2), 216-226. Disponível em: https://www.scielo.br/pdf/alea/v17n2/1517-106X-alea-1702-00216.pdf.

Kohan, W. O., \& Durán, M. (2017). Perguntar. In: Costa, L.B. Bandeira, L.B. Corrêa, T.M. (orgs). Estátuas de Nuvens: dicionário de palavras pesquisadas por infâncias. Porto Alegre: Editora Sulina, p. 175-183.

Latour, B. (2004/2019). Políticas da Natureza. São Paulo: Editora UNESP.

Latour, B. (2005). Reassembling the social: An introduction to actor network theory. Oxford: Oxford University Press

Masny, D. (2013). Cartographies of Becoming in Education. A Deleuze-Guattari Perspective. Rotterdam: Sense Publishers

Naranjo, J. (2009). Casa de las estrellas. El universo contado por los niños. Madrid: Ed. Aguilar.

Oliveira, T. Paraíso, M. Mapas, dança, desenhos: a cartografia como método de pesquisa em educação. Pro-Posições | v. 23, n. 3 (69) | p. 159-178 | set./dez. 2012. Disponível em: https://www.scielo.br/pdf/pp/v23n3/10.pdf

Oswell, D. (2013). The Agency of Children: From Family to Global Human Rights. Cambridge: Cambridge University Press.

Oswell, D. (2016). Re-aligning children's agency and re-socialising children in Childhood Studies. In. F. Esser, M. Baader, T. Betz, \& B. Hugerland (2016). Reconceptualising Agency and Childhood [VitalSource Bookshelf version]. Retrieved from vbk:/ /9781317524403

Passos, E., Barros, R. (2009). A Cartografia como método de pesquisa-intervenção. In E. Passos, V. Kastrup. L. Escóssia (eds.). Pistas do método da cartografia. Porto Alegre: Sulina.

Passos, E.; Kastrup, V.; Escóssia, L. (2009). Pistas do método da cartografia. Porto Alegre: Sulina.

Passos, E., Kastrup, V., Escóssia, L. (2009). Introdução. In E. Passos, V. Kastrup. L. Escóssia (eds.).Pistas do método da cartografia. Rio de Janeiro: Sulina.

Passos, E., Kastrup, V. (2013). Sobre a validação da pesquisa cartográfica: acesso à experiência, consistência e produção de efeitos. Fractal: Revista de Psicologia, 25(2), 391-413.

Passos, E.; Kastrup, V.; Tedesco, S. (2014). Pistas do método da cartografia: a experiência da pesquisa e o plano comum. Vol. 2. Porto Alegre: Sulina.

Paulon, S., \& Romagnoli, R. (2010). Pesquisa-intervenção e cartografia: melindres e meandros metodológicos. Estudos e pesquisas em Psicologia, 1, 1, 85-102.

Prout, A. (2005). The Future of Childhood. London: Routledge Falmer.

Rolnik, S. (1989). Cartografia sentimental: transformações contemporâneas do desejo. São Paulo: Estação Liberdade.

Santos, A. M. (2018). Editorial. Educação, 41(2), 163-164. Disponível em: https://revistaseletronicas.pucrs.br/ojs/index.php/faced/article/view/31812

Sarmento, M. J. (2015). Uma Agenda Crítica para os Estudos da Criança. Currículo sem Fronteiras, 15(1), 31-49.

Semenec. P. \& Diaz-Diaz, C. (2020). Posthumanist and New Materialist Methodologies: Research After the Child. Amesterdam: Sringer.

Serres, M. (1996). O Terceiro Instruído. Lisboa: Edições Piaget.

Silva, F.S. (2017). Aprendendo com a loucura. In: Costa, L.B. Bandeira, L.V. Corrêa, T.M. (orgs). Estátuas de Nuvens: dicionário de palavras pesquisadas por infâncias. Porto Alegre: Editora Sulina, 235-237.

Sellers, M. (2013). Young Children Becoming Curriculum [VitalSource Bookshelf version]. vbk:/ / 9781136280023 
cartografia infantil: enfoques metodológicos seguidos de experiências com crianças e jovens de portugal e brasil

Taylor, A. (2013). Reconfiguring the Natures of Childhood. [VitalSource Bookshelf 9.2.1]. vbk:/ /9781136672170

Teti, K. Filho, M. (2013). A cartografia como método para ciências humanas e sociais. Revista Barbarói, n.38, 2013/1, p.45-59. Disponível em: https://online.unisc.br/seer/index.php/barbaroi/article/view/2471/2743

Weldemariam, K., \& Wals, A. (2020). From Autonomous Child to A Child Entangled Within an Agentic World - Implications for Early Childhood Education For Sustainability. In S. Elliot, E. Arlemalm-Hagsér, \& J. Davis (2020). Researching Early Childhood Education for Sustainability - Challenging Assumptions and Orthodoxies. Routhledge. [VitalSource Bookshelf version].

Wunder, A. (2016). Das imagens que movem o pensar. In: Scareli, G. Fernandes, P. (orgs). O que te move a pesquisar? Ensaios e experimentações com cinema, educação e cartografias. Porto Alegre: Editora Sulina.

submetido em: 06.01.2021

aprovado em: 18.02 .2021 